\title{
Toxicity of sesame extracts to the symbiotic fungus of leaf-cutting ants
}

\author{
Fernando Carlos Pagnocca \\ Osvaldo Aulino da Silva \\ Maria Jose Hebling-Beraldo \\ Odair Correa Bueno \\ Instituto de Biociências, Universidade Estadual Paulista \\ Rio Claro, São Paulo, Brasil \\ João Batista Fernandes \\ Paulo Cesar Vieira \\ Departamento de Quimica-Universidade Federal de São Carlos
São Carlos-São Paulo-Brasil

\begin{abstract}
Extracts of different sesame plant (Sesamum indicum) Linnaeus organs inhibited the in vitro growth of the fungus Leucocoprinus gongylophorus (Möller) (=Rozites gongylophora Möller), which is cultivated by the leaf-cutting ants of the species Atta sexdens rubropilosa Forel (Hymenoptera: Formicidae). The presence of the factor responsible for this inhibition was detected in methanol or chloroform extracts and is constant in the plant.
\end{abstract}

\section{Introduction}

Leaf-cutting ants (Atta spp. and Acromyrmex spp.) which are distributed from Argentina to the southern United States, cause serious damage to a wide variety of plants and are a serious crop pest. In natural ecosystems, the ants show preference for some plant species which are constantly defoliated, whereas others are not attacked even though they are abundant and located close to the nests (Cherrett, 1968; Hubbell \& Wiemer, 1983; Littledyke \& Cherrett, 1975; Rockwood, 1976, 1977). Attraction or repellence may be influenced by different properties of leaves, such as density, hardness, moisture level, nutritional quality, and secondary metabolites (Hubbell \& Wiemer, 1983; Hubbell et al., 1984).

The complex interrelationships between phytophagous insects and plants are the result of a long and continuous evolutionary process which involves the development of defence mechanisms by the plants and adaptation of leaf-cutting ants to such mechanisms

Correspondence: Dr F.C. Pagnocca, Instituto de Biociências, Universidade Estadual Paulista, P.O. Box 178-13,500, Rio Claro, São Paulo, Brasil.
(Febvay \& Kermarrec, 1986).

There is some experimental evidence that secondary metabolites present in certain plants may be harmful to leaf-cutting ants and to their symbiotic fungus (Howard et al., 1988). Bueno et al. (in press) detected a gradual regression in number of individuals and size of fungal mass up to full extinction of nests maintained in the laboratory and treated with sesame leaves (Sesamum indicum L.).

The main objective of the present study was to test the hypothesis that the harmful effects of sesame on nests of Atta sexdens rubropilosa Forel, may be the consequence of secondary compounds present in this plant that are toxic to the symbiotic fungus.

\section{Material and methods \\ Preparation of S. indicum crude extracts}

The extracts were prepared from different plant organs at the following developmental stages: $\mathrm{L} 1$ = leaves obtained from 30 -day old plants; $\mathrm{L} 2$ = leaves obtained from 60-day old plants; L3a = green leaves from 90-day old plants; L3b = yellow leaves obtained from 90day old plants; $\mathrm{GFr}=$ green fruit; $\mathrm{RFr}=$ ripe fruit; 
GS = green seed; RS = ripe seed. Chloroform, methanol and water were used as solvents. Extracts were prepared by drying and grinding the material and soaking a known amount of each in excess solvent. After 72 hours of contact with intermittent shaking, the material was filtered through paper and $1 \%$ activated charcoal $(w / v)$ was added to the filtrate. The mixture was stirred with a magnetic bar for one hour and filtered through paper several times. After the last filtration, the extract was refrigerated until the time for use.

\section{Microorganism}

The fungus Leucocoprinus gongylophorus (Möller) $(=$ Rozites gongylophora Möller) was isolated from a nest of Atta sexdens rubropilosa.

\section{Culture medium}

The following culture medium $(\mathrm{g} / \mathrm{l})$ was used both for the assays and for maintenance of the fungus: glucose $=10 ;$ sodium chloride $=5$; bacto-peptone $=5$; malt extract $=10$ and agar $=15$. Sesame extracts were added to the medium to a final concentration of 7.5 to 60 $\mathrm{mg}$ dry leaf weight $/ \mathrm{ml}$ and the mixture was autoclaved for 15 minutes at $120^{\circ} \mathrm{C}$. Thirty-day cultures developed in $250 \times 25 \mathrm{~mm}$ tubes containing $20 \mathrm{ml}$ solid medium were used for obtaining the mycelial mass for the inoculum.

\section{Inoculum preparation}

To provide similar inoculum size in each experiment we worked with cultures about 30 days old. The mycelium present in five or six stock culture tubes was transferred aseptically to a glass tissue grinder $(250 \times 25 \mathrm{~mm})$ to which $3.0 \mathrm{ml}$ sterile saline had been added. The material was weakly fragmented and diluted to about $120 \mathrm{ml}$ with sterile saline. This procedure enabled us to get an inoculum containing about 3 or $4 \mathrm{mg}$ of dry weight $/ \mathrm{ml}$, which was added to tubes containing slanted medium. The tubes were carefully shaken to provide a good distribution of mycelial fragments on agar slant and incubated at room temperature $\left(25 \pm 2{ }^{\circ} \mathrm{C}\right)$. Hyphal dispersal was monitored by light microscopy to avoid excessive fragmentation during homogenization. The assays were run with 10 test tubes/sample and repeated three times for leaf extracts and twice for other material.

\section{Growth evaluation}

Fungal growth was estimated macroscopically on the basis of mycelial surface and density after 30-35 days incubation. Controls received the same amount of solvent, and relative growth was characterized as follows: $5+=$ growth identical to control; $4+=$ growth equivalent to $80 \%$ of control; $3+=$ growth equivalent to $60 \%$ of control; $2+=$ growth equivalent to $40 \%$ of control; $1+=$ growth equivalent to $20 \%$ of control or less.

\section{Analysis of sesamine in $\mathrm{S}$. indicum}

To determine the possible occurrence of sesamine in different organs of the sesame plant, L1, L2, L3, GFr, RFr,
GS, and RS extracts were prepared using dichloromethane and methanol as solvents. The extracts were analysed by thin silica gel layer chromatography using dichloromethane: ethyl acetate (9:1) as the eluent system and sesamine as the standard, and also by obtaining Proton Nuclear Magnetic Resonance (NMR'H FT-80) spectra, with $0.1 \mathrm{mg}$ sensitivity under the conditions of analysis used.

\section{Results}

The data in table 1 show that the methanol and chloroform extracts produced varying degrees of inhibition of fungal development. This effect could be seen starting at concentrations of $>30 \mathrm{mg}$ dry leaf weight $/ \mathrm{ml}$. Small variations in the degree of fungal development were occasionally observed depending on inoculum concentration. The aqueous extract was responsible for a small stimulation of fungal growth.

The results presented in table 2 indicate that the factor responsible for fungal inhibition is distributed through several organs of the sesame plant. In addition,

Table 1. Antifungal activity of sesame leaf extracts

\begin{tabular}{lcc}
\hline Solvent & $\begin{array}{c}\text { Final concentration } \\
\text { mg leaf dry weight } / \mathrm{ml}\end{array}$ & $\begin{array}{c}\text { Fungus relative } \\
\text { growth } \\
(30-35 \text { days })\end{array}$ \\
\hline Chloroform & 7.5 & $5+$ \\
& 15.0 & $5+$ \\
& 30.0 & $4+$ \\
& 60.0 & $2+$ \\
Methanol & 7.5 & $5+$ \\
& 15.0 & $5+$ \\
& 30.0 & $2+$ \\
Chlorof.+Methanol & 60.0 & $2+$ \\
& $30.0+30.0$ & $<1+$ \\
Water & $60.0+60.0$ & $>5+$ \\
\hline
\end{tabular}

$5+=$ growth identical to control; $4+=$ growth equivalent to $80 \%$ of control; $3+=$ growth equivalent to $60 \%$ of control; $2+=$ growth equivalent to $40 \%$ of control; $1+=$ growth equivalent to $20 \%$ of control of less

Table 2. Antifungal activity of chloroform extracts of sesame leaves, fruits and seeds at different stages of development.

\begin{tabular}{lcc}
\hline $\begin{array}{l}\text { Material and } \\
\text { developmental stage }\end{array}$ & $\begin{array}{c}\text { Final concentration } \\
\text { mg dry weight } / \mathrm{ml}\end{array}$ & $\begin{array}{c}\text { Fungus relative } \\
\text { growth } \\
\text { (30-35 days) }\end{array}$ \\
\hline L1 (leaves 30 days old) & 60.0 & $2+$ \\
L2 (leaves 60 days old) & 60.0 & $2+$ \\
L3a (green leaves & & $3+$ \\
$\quad$ 90 days old) & 60.0 & $2+$ \\
L3b (yellow leaves & & $3+$ \\
$\quad 90$ days old) & 60.0 & $2+$ \\
GFr (green fruit) & 30.0 & $2+$ \\
RFr (ripe fruit) & 30.0 & $2+$ \\
GS (green seed) & 30.0 & \\
RS (ripe seed) & 30.0 & \\
\hline
\end{tabular}

Control $=5+$ 
the data demonstrate that ripe fruit and seed extracts caused marked inhibition of fungal growth at lower concentrations than leaf extracts. No seasonal variation was detected in the inhibiting factor.

Analysis of $\mathrm{NMR}^{1} \mathrm{H}$ spectra of all extracts from the different organs of the sesame plants indicated that none had detectable amounts of sesamine. Thin silica gel layer chromatography indicated the presence of a spot having the same Rf as sesamine, although of slight staining intensity, in green and ripe seed extracts. Since the sensititivy of this method is higher, these fractions were resubmitted to thin-layer chromatography, but were insufficient to be detected by $\mathrm{NMR}^{1} \mathrm{H}$.

\section{Discussion and conclusion}

The results indicate that different organs of Sesamum indicum contain compounds inhibiting the development of the fungus cultivated by Atta sexdens rubropilosa. These compounds, which have not yet been chemically purified, are liposoluble and may or may not present polarity, as indicated by the effects obtained with chloroform or methanol extracts.

The occurrence of liposoluble substances endowed with antifungal properties involves different groups of plants and fungi, as reported by Maizel et al. (1964) for Avena sativa (oats) and by Kubo \& Taniguchi (1988) for two Walburgia spp. (Canallaceae). Compounds that repel leaf-cutting ants have been found in the lipid fraction of plant extracts (Littledyke \& Cherrett, 1978; Mudd et al., 1978) and most of them belong to the terpenoid group. Many of these compounds also have antifungal activity (Howard \& Wiemer, 1986; Howard et al., 1988; Hubbell et al., 1984; Wiemer, 1985).

Secondary metabolites present in plants having a repellent action act as indicators of potential danger for leaf-cutting ants. These compounds may cause ant death directly through sap ingestion, or indirectly by reducing the amount of symbiotic fungus. In the latter case, larvae would be deprived of their source of nutrients (Quinlan \& Cherrett, 1979). The consequence of these phenomena may be the extinction of ants' nests, as observed by Mullenax (1979) and Bueno et al. (in press).

The repellent action of these secondary metabolites and the damage they may cause to the symbiont fungus may explain one of the aspects of the trophic relationship between plants and leaf-cutting ants. Rockwood (1976) suggested that the selection of plants to be attacked by leaf-cutting ants involves maximum nutritional content and minimum harmful effects for the fungus.

The fact that $S$. indicum leaves are voraciously attacked by ants suggests that the presence of attracting or stimulating compounds may be masking the occurrence of possible repellents. The avidity of ants for $S$. indicum leaves also occurs in relation to a large number of introduced species (Littledyke \& Cherrett, 1975) and may be explained by the absence of co-evolution.

The results also show that inhibition of fungal growth is not due to sesamine, since sesamine was not detected in sesame leaves. This compound, a furfuranic lignan, has been utilized as a synergistic factor in insecticides (O'Brien, 1967). According to Budowski (1964), sesamine is found in several plants, but in sesame it is restricted to seeds and its synthesis occurs simultaneous- ly with that of the oil, from which it can be extracted (Lyon, 1972). The factor inhibiting the development of the symbiont fungus is present in the various organs of the sesame plant and this may be of fundamental importance for its extraction and purification. In addition, the factor does not show seasonal occurrence, contrary to what was suggested by Fowler \& Stiles (1980) and by Howard (1987) in relation to other secondary metabolites of different plant species.

\section{Acknowledgements}

This work has been supported by Conselho Nacional de Desenvolvimento Científico e Tecnológico (CNPq), Fundação Para o Desenvolvimento da UNESP (FUNDUNESP) and Fundação Banco do Brasil (FIPEC).

\section{References}

Budowski, P. (1964) Recent research on sesamin, sesamolin, and related compounds. The Journal of the American Oil Chemist's' Society 41, 280-285.

Bueno, O.C., Hebling-Beraldo, M.J.A., Aulino da Silva, O. \& Matenhauer, A.M. Effects of the sesame (Sesamum indicum L.) on the nests development of Atta sexdens rubropilosa Forel. Insect Sociaux (in press).

Cherrett, J.M. (1968) The foraging behaviour of Atta cephalotes (L.) (Hymenoptera: Formicidae). I. Foraging patterns and plant species attacked in tropical rain forest. Journal of Animal Ecology 37, 387-403.

Febvay, G. \& Kermarrec, A. (1986) Prevention of feeding by Acromyrmex octospinosus with antifeedants from yams. pp. 247-259 in Lofgren, C.S. \& Vander Meer, R.K. (Eds.). Fire ants and leaf-cutting ants. 435 pp. Boulder, USA, Westview Press.

Fowler, H.G. \& Stiles, E.W. (1980) Conservative resource management by ieaf-cutting ants? The role of foraging territories and trails and environmental patchiness. Sociobiology 5 , 25-41.

Howard, J.J. (1987) Leafcutting ant diet selection: the role of nutrients, water and secondary chemistry. Ecology 68, 503-515.

Howard, J.J. \& Wiemer, D.F. (1986) Chemical ecology of host plant selection by the leaf-cutting ant Atta cephalotes. pp. 260 273 in Lofgren, C.S. \& Vander Meer, R.K. (Eds). Fire ants and leaf-cutting ants. 435 pp. Boulder, USA, Westview Press.

Howard, J.J., Cazin J. \& Wiemer, D.F. (1988) Toxicity of terpenoid deterrents to the leafcutting ant Atta cephalotes and its mutualistic fungus. Journal of Chemical Ecology 14, 59-69.

Hubbell, S.P. \& Wiemer, D.F. (1983) Host plant selection by an Attine ant. pp. 133-154 in Jaisson, P. (Ed.). Social Insects in the Tropics 5, 133-153.

Hubbell, S.P., Howard, J.J. \& Wiemer, D.F. (1984) Chemical leaf repellency to an Attine ant: Seasonal distribution among potential host plant species. Ecology 65, 1067-1076.

Kubo, I. \& Taniguchi, M. (1988) Polygodial, an antifungal potentiator. Journal of Natural Products 5, 22-29.

Littledyke M. \& Cherrett, J.M. (1975) Variability in the selection of substrate by the leaf-cutting ants Atta cephalotes (L.) and Acromyrmex octospinosus (Reich) (Formicidae, Attini). Bulletin of Entomological Research 65, 33-47.

Littledyke, M. \& Cherrett, J.M. (1978) Defence mechanisms in young and old leaves against cutting by the leaf-cutting ants Atta cephalotes (L.) and Acromyrmex octospinosus 
(Reich) (Hymenoptera: Formicidae). Bulletin of Entomological Research 68, 263-271.

Lyon, K.C. (1972) Sesame: current knowledge of composition and use. Journal of the American Oil Chemists' Society 49, 245-249.

Maizel, J.V., Burkhardt, H.J. \& Mitchell, H.K. (1964) Avenacin, an antimicrobial substance isolated from Avena sativa. I. Isolation and antimicrobial activity. Biochemistry 3, 424-426.

Mudd, A., Peregrine, D.J. \& Cherrett, J.M. (1978) The chemical basis for the use of citrus pulp as a fungus substrate by the leafcutting ants Atta cephalotes (L.) and Acromyrmex octospinosus (Reich) (Hymenoptera: Formicidae). Bulletin of Entomological Research 68, 673-685.

Mullenax, C.H. (1979) The use of jackbean (Canavalia ensiformis) as a biological control for leaf-cutting ants (Atta spp.). Biotropica 11, 313-314.
O'Brien, R.D. (1967). Insecticides: action and metabolism. 332 pp. New York, USA, Academic Press.

Quinlan, R.J. \& Cherrett, J.M. (1979) The role of fungus in the diet of the leaf-cutting ant Atta cephalotes (L.). Ecological Entomology 4, 151-160.

Rockwood, L.L. (1976) Plant selection and foraging patterns in two species of leaf-cutting ants (Atta). Ecology 57, 48-61.

Rockwood, L.L. (1977) Foraging patterns and plant selection in Costa Rica leaf cutting ants. Journal of the New York Entomological Society 85, 222-233.

Wiemer, D.F. (1985) Natural repellents of the leaf cutter ants. Revista Latinoamericana de Quimica 16, 98-101.

(c) C.A.B International, 1990 